\title{
Feasibility Study of Reactive Distillation Column for Transesterification of Palm Oils
}

\author{
Chokchai Mueanmas, Kulchanat Prasertsit* and Chakrit Tongurai
}

\begin{abstract}
The production of biodiesel by transesterification in existing processes requires excess alcohol, typically $100 \%$, over its stoichiometric requirement in order to drive the chemical reaction to complete. This excess alcohol must be recovered and purified for reusing by rectification and distillation, which involves additional capital and operating costs. Therefore, combination of reactor and distillation column in only one unit called reactive distillation column (RD) may lead to an enormous capital-investment cost reduction. This research is proposed the feasibility study of biodiesel production from palm oil by transesterification using reactive distillation. The hypothesis is to reduce the amount of alcohol in the feed stream closing to its stoichiometric ratio with oil. This dues to the less energy used in the methanol recovery for the processes. The effects of process parameters were conducted by lab scale RD packed column. The results indicated that process parameters of $900 \mathrm{ml} / \mathrm{hr}$ flow rate, reboiler temperature $90^{\circ} \mathrm{C}$ with 4.0:1 molar ratio of methanol to oil and residence time of 5 minutes in the column produced 92.75 percent biodiesel purity.
\end{abstract}

Index Terms-Biodiesel, Palm oil, Reactive Distillation, Transesterification

\section{INTRODUCTION}

The concept of biodiesel as an alternative diesel fuel has been gaining great importance worldwide for its good quality exhaust, sustainability, biodegradability and can be used in conventional diesel engines without significant modifications [1] - [3]. Biodiesel, referred to monoalkyl esters, is derived from vegetable oils or animal fats, and low molecular weight alcohols in the presence of catalysts as shown in fig.1. Biodiesel can be produced from any material that contains fatty acids such as vegetable fats and oils, animal fats, waste greases or edible oil processing wastes. The choice of feedstock is based on local availability, cost, government support or performance as a fuel.

Using direct vegetable oil or blending with fuel oil is not satisfied for the diesel engine because of the high viscosity, acid composition, free fatty acid content, gum formation and carbon decomposition that may cause some problems such as oxidation and polymerization during storage and combustion [4]. To solve the problem, there are many techniques for converting the vegetable oil to biodiesel such as transesterification, pyrolysis, enzyme lipase, super critical fluid extraction. A summary of the advantages and disadvantages of each technological possibility to produce

Chokchai Mueanmas, Kulchanat Prasertsit and Chakrit Tongurai, Department of Chemical Engineering, Faculty of Engineering, Prince of Songkla University, Songkhla, 90112, Thailand

Corresponding author. Tel.: +6674-287289; fax: +6674-212896 (e-mail address: kulchanat.k@psu.ac.th). biodiesel could be found in Table 1 [5].

The current conventional processes, however, have several disadvantages: shifting the equilibrium to fatty esters by using an excess of alcohol that must be separated and recycled, making use of homogeneous catalysts that requires neutralization (causing salt waste streams), expensive separation of products from the reaction mixture, and high costs due to complex processes involving one to two reactors and several separation units. From these reasons, using biodiesel has not expanded into developing countries, due to the prices close to or higher than the cost of diesel. The higher cost of biodiesel is due to its production mostly from expensive high-quality virgin oil [6] and consists of many units. Therefore, to solve these problems, the bringing of reactive distillation (RD) apply in the production process lead to enormous reduction of capital and investment cost.

Reactive distillation (RD) is an innovating process which combines both distillation and chemical reaction into a single unit [7], which saves energy (for heating) and materials. Therefore, the RD technology offers many benefits as well as restrictions over the conventional process of reaction followed by distillation or other separation approaches. Reducing capital cost [8], higher conversion, improving selectivity [9], lower energy consumption, the reduction or elimination of solvents in the process [10] and voidance of azeotropes [11] are a few of the potential advantages offered by RD. This technique is especially useful for equilibrium-limited reactions such as esterification and transesterification reactions. Conversion can be increased far beyond what is expected by the equilibrium due to the continuous removal of reaction products from the reactive zone. This helps to reduce capital and investment costs and may be important for sustainable development due to a lower consumption of resources.

The goal of this study is to test a lab scale continuous flow reactive distillation and its applicability for biodiesel production. The hypotheses were (1) applicable for biodiesel production, (2) reducing the amount of alcohol, (3) shorten the reaction time.

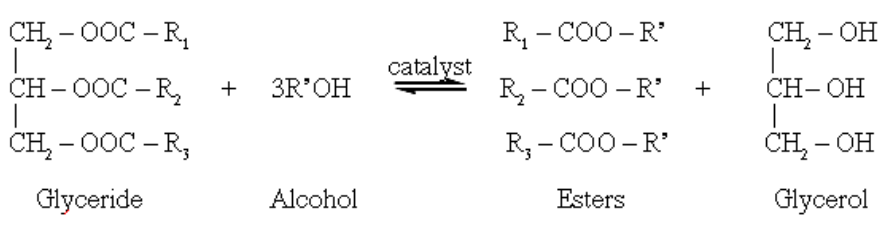

Figure 1: the reaction of a fat or oil with an alcohol to form esters and glycerol 
TABLE 1. Comparison of The Different Technologies to Produce Biodiesel

\begin{tabular}{|c|c|c|c|c|}
\hline Variable & Alkali catalysis & Lipase catalysis & $\begin{array}{c}\text { Supercritical } \\
\text { alcohol }\end{array}$ & Acid catalysis \\
\hline Reaction temperature $\left({ }^{\circ} \mathrm{C}\right)$ & $60-70$ & $30-40$ & $239-385$ & $55-80$ \\
\hline Free fatty acid in raw materials & Saponified products & Methyl esters & Esters & Esters \\
\hline Water in raw materials & $\begin{array}{l}\text { Interference with } \\
\text { reaction }\end{array}$ & No influence & & Interference with reaction \\
\hline Yield of methyl esters & Normal & Higher & Good & Normal \\
\hline Recovery of glycerol & Difficult & Easy & & Difficult \\
\hline Purification of methyl esters & Repeated washing & None & & Repeated washing \\
\hline Production cost of catalyst & Cheap & Relatively expensive & Medium & Cheap \\
\hline
\end{tabular}

\section{MATERIALS AND METHODS}

\section{Chemicals and Reagent}

Palm oil and methanol were used as the reactants with potassium hydroxide catalyst in this work. The palm oil contained free fatty acid about $0.3-0.6 \%$ and less than $1 \%$ moisture content. Commercial grade methanol was used as the alcohol source in all experiments. A litre of methanol was premixed with $100 \mathrm{~g}$ potassium hydroxide to form potassium methoxide before being pumped into the RD.

\section{Equipment}

A continuous flow RD reactor system as shows in fig. 2 was developed and tested on overall process parameters. The $\mathrm{RD}$ is packed column with maintain top column temperature at $64^{\circ} \mathrm{C}$.

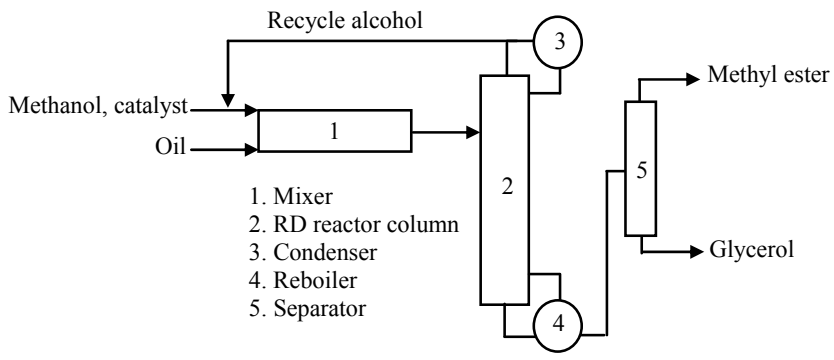

Figure 2: Biodiesel production process with reactive distillation.

\section{Experimental}

Startup Procedures:

To start of each experiment, approximate $2 \mathrm{~L}$ of oil and $250 \mathrm{~mL}$ of methanol were injected into the column. The reboiler heater was set to $120^{\circ} \mathrm{C}$ and allowed to heat for approximately 1.5 hours till the temperature of the top column reached $64^{\circ} \mathrm{C}$. The actual flow rate, ratio of methanol to oil and temperature profile along the column each experiment were show in table 2.

\section{Steady-operation:}

The inputs, both oil at $85^{\circ} \mathrm{C}$ and methanol at $30^{\circ} \mathrm{C}$, were pumped into a short tube mixer to mix the oil with the methanol/catalyst solution. Then the reactant mixture at $65^{\circ} \mathrm{C}$ was entered to the top of the RD column. In the RD column, triglyceride in the reactant mixture further reacted with the present methanol. The product mixture was withdrawn from the reboiler section and sent to a glycerolester separator, where the glycerol and esters were separated by gravity in a continuous mode.

Every hour, samples were collected from reboiler to analyst the biodiesel composition and methanol content.

\section{Product analysis}

\section{- Gas Chromatography}

The content of FAME in product was analyzed by a GC7890 gas chromatography (Agilent 7890A). Its column is a SelectTM Biodiesel for fatty acid methyl ester (FAME) capillary column (length $30 \mathrm{~m}$ x $320 \mu \mathrm{m}$ I.D. x $0.25 \mu \mathrm{m}$ film thickness, Varian Part No. CP-9080). Initial column temperature was $210^{\circ} \mathrm{C}$ and kept it for $12 \mathrm{~min}$, then was raised to $250^{\circ} \mathrm{C}$ at the rate of $20^{\circ} \mathrm{C} / \mathrm{min}$ and maintained this temperature for $8 \mathrm{~min}$. The temperature of the injector and the flame ionization detector (FID) was 290 and $300{ }^{\circ} \mathrm{C}$, respectively. The content of ester FAME was quantitatively determined using the concentration of methyl heptadecanoate (C17:0, internal standard).

\section{Calculations:}

The ester content ( $C$ ) expressed as a fraction in percent, is calculated using the following formula:

$$
C=\frac{\left(\sum A\right)-A_{E I}}{A_{E I}} \times \frac{C_{E I} x V_{E I}}{m} \times 100 \%
$$

$\sum A=$ the total peak area from the FAME $\mathrm{C}_{14: 0}$ to $\mathrm{C}_{24: 1}$

$A_{E I}=$ the peak area of methyl heptadecanoate

$C_{E I}=$ the concentration, in $\mathrm{mg} / \mathrm{mL}$, of the methyl heptadecanoate solution

$V_{E I} \quad=$ the volume, in $\mathrm{mL}$, of the methyl heptadecanoate solution

$m \quad=$ the mass, in mgr, of the sample 


\begin{tabular}{|c|c|c|c|c|c|c|c|c|}
\hline \multirow{3}{*}{ Trial ID } & \multirow{3}{*}{ Molar Ratio } & \multicolumn{2}{|c|}{ Feed rate $(\mathrm{ml} / \mathrm{hr})$} & \multicolumn{5}{|c|}{ Temperature $\left({ }^{\circ} \mathrm{C}\right)$} \\
\hline & & \multirow{2}{*}{ Oil } & \multirow{2}{*}{ Methanol } & \multirow{2}{*}{ Reboiler } & \multicolumn{4}{|c|}{ Column height $(\mathrm{m})$} \\
\hline & & & & & 1 & 2 & 3 & 4 \\
\hline 2 & $4.0: 1$ & 900 & 157.56 & $85-120$ & 70 & 64 & 64 & 64 \\
\hline 3 & $5.0: 1$ & 900 & 196.94 & $85-120$ & 70 & 64 & 64 & 64 \\
\hline 4 & $6.0: 1$ & 900 & 236.33 & $85-120$ & 70 & 64 & 64 & 64 \\
\hline
\end{tabular}

Sample Preparation:

Accurately weigh approximately $250 \mathrm{mg}$ of sample in a $10 \mathrm{~mL}$ vial, then add $5 \mathrm{~mL}$ of methyl heptadecanoate solution $(10 \mathrm{mg} / \mathrm{mL})$ using a pipette.

\section{Calculations:}

The ester content ( $C$ ) expressed as a fraction in percent, is calculated using the following formula:

$$
C=\frac{\left(\sum A\right)-A_{E I}}{A_{E I}} \times \frac{C_{E I} x V_{E I}}{m} \times 100 \%
$$

$\sum A=$ the total peak area from the FAME $\mathrm{C}_{14: 0}$ to $\mathrm{C}_{24: 1}$

$A_{E I}=$ the peak area of methyl heptadecanoate

$C_{E I}=$ the concentration, in $\mathrm{mg} / \mathrm{mL}$, of the methyl heptadecanoate solution

$V_{E I} \quad=$ the volume, in $\mathrm{mL}$, of the methyl heptadecanoate solution

$m \quad=$ the mass, in mgr, of the sample

- Thin Layer Chromatography

The compositions of the reaction mixture samples were determined by a thin layer chromatography equipped with flame ionization detector (TLC-FID) using an Itronscan MK-6s with Chromarods type S-III quartz rod (Mitshubishi Kagaku Iatron). One microliter of the reaction medium, diluted in hexane at appropriate dilution, was spotted onto chromarods.

- Firstly, chromarods were immersed in a solvent mixture of hexane:diethyl ether:formic acid (50:20:0.3 v/v) until the solvent reaching to $8 \mathrm{~cm}$ (approximately $15 \mathrm{~min}$ ).

- Secondly, the chromarods were immersed in a solvent mixture of benzene:hexane $(50: 50 \mathrm{v} / \mathrm{v}$ ) for about $35 \mathrm{~min}$ (or until the solvent reach to $10 \mathrm{~cm}$ ).

- The spotted samples were developed in these two solvent mixtures. The chromarods were then dried at $105{ }^{\circ} \mathbf{C}$ for $5 \mathrm{~min}$ and scanned with TLC-FID.

- Scanning was performed using a $160 \mathrm{ml} / \mathrm{min}$ of hydrogen flow rate and $20 \mathrm{l} / \mathrm{min}$ of air flow rate to produce a chromatogram.

- The compositions were calculated as wt $\%$ based on the peak areas of each component.

\section{- Methanol content}

Unreacted methanol in product, both ester and glycerol, was determined by weighing before and after evaporation in vacuum distillation at $50^{\circ} \mathrm{C}$.

\section{RESUlt AND DiscUSSION}

The palm oil component studied by thin layer chromatography (TLC) is shown in fig. 3. It was found that the palm oil consist of $0.58 \%$ of free fatty acid (fig. 4), can use directly to transesterification reaction.

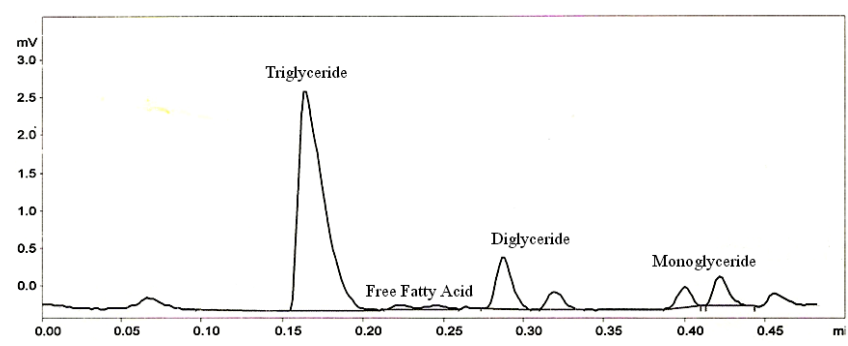

Figure 3: The analysis result of palm oil component by TLC

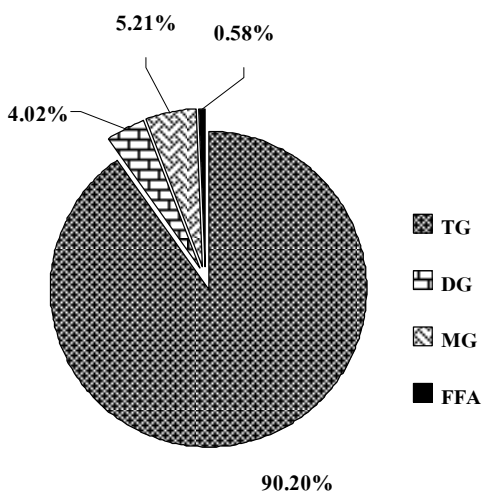

Figure 4: The palm oil composition.

The fatty acid methyl ester profile of the palm oil was analyzed using the GC method (EN-14103) and is shown in fig. 5 and fig. 6.

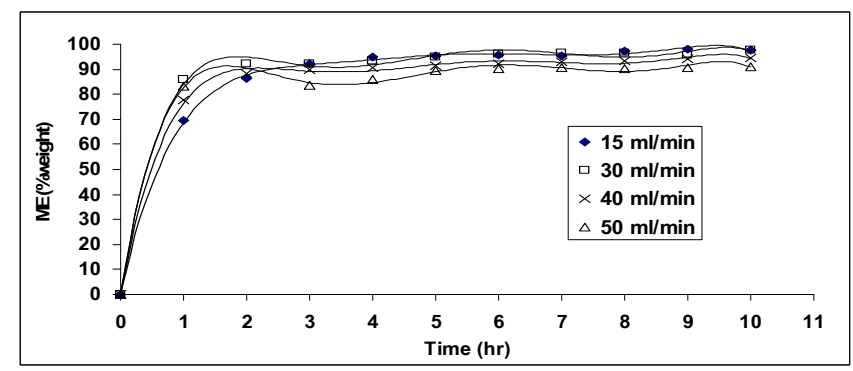

Figure 7: Effect of flow rate on methyl esters content in product at varying time. 


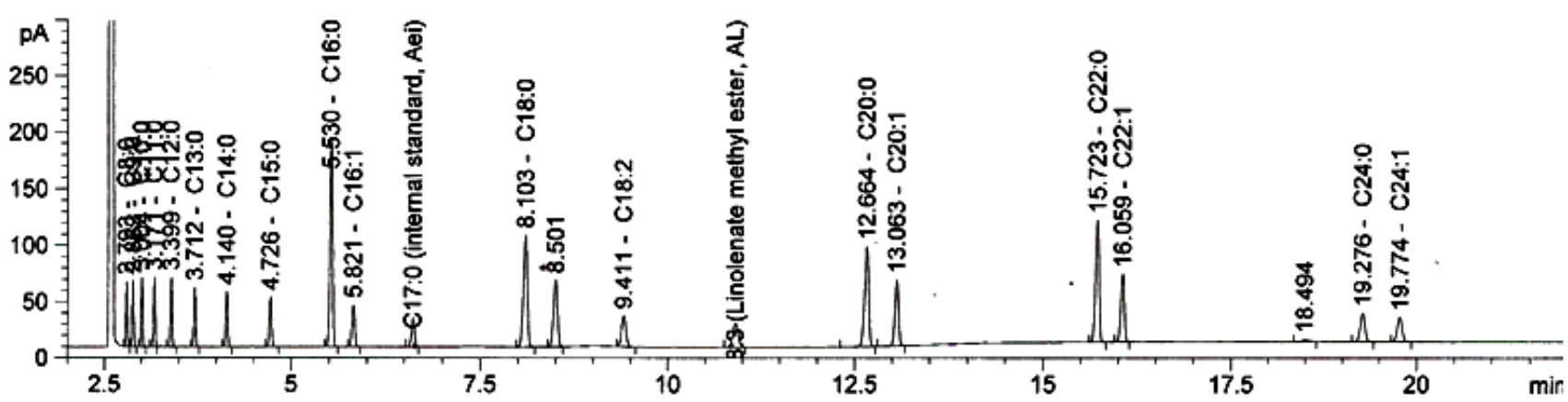

Figure 5: Chromatogram of standard fatty acid methyl ester (C8 - C24).

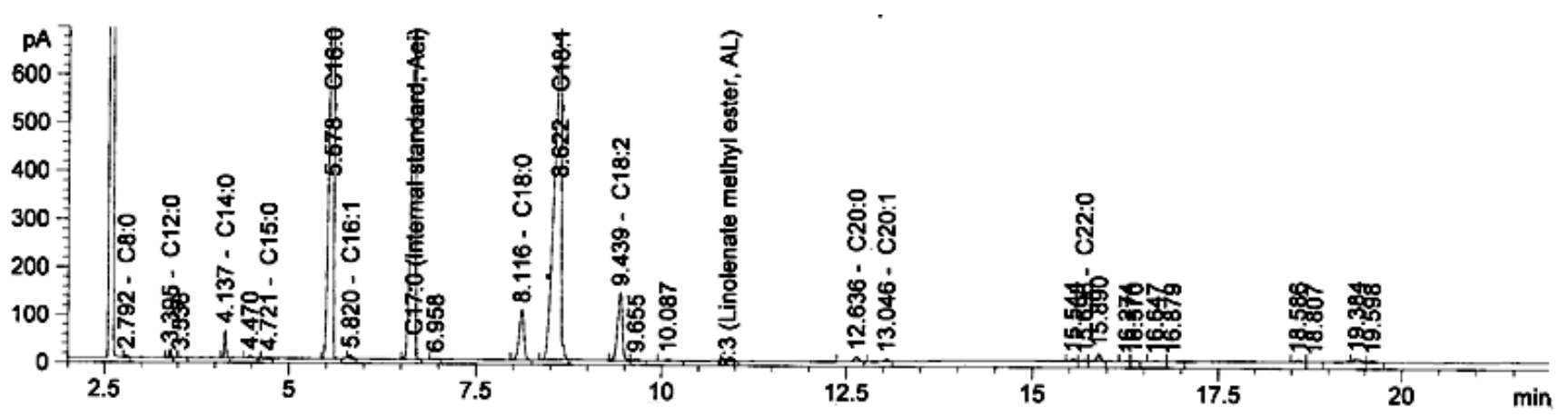

Figure 6: Chromatogram of fatty acid methyl ester from palm oil.

\section{The physical appearance of tranesterified products}

Transesterified products are separated into 2 phases. They are methyl ester in top phase and glycerol in bottom phase. The unreacted methanol dissolves in both phases. The appearance of transesterified product is shown that, at low temperature, the product was easy separated by gravity but can not separate at high temperature. At the high temperature, the rate of soap formation increases more rapidly than transesterification. The soap is occurred by saponification reaction between oil or biodiesel with catalyst, which consumes the catalyst and causes decreasing of reaction conversion. Then, glycerol could dissolve in methyl ester phase.

\section{Effect of flow rate}

The feed stream flow rates for the test run were chosen carefully in order to avoid any column flooding problem. The flow rate, which is inversely related to retention time, is used as an experimental factor to interpret the reaction conversion with the liquid retention time. The total column volume of approximately $75 \mathrm{~mL}$. The flow rate achieved in the experimental varied from 15 to $60 \mathrm{~mL} / \mathrm{min}$. The retention time varied from about 5 to $1.25 \mathrm{~min}$. These values may not be the actual reaction time because of some reaction that takes place in the reboiler. Since the concentrations of methanol and catalyst were very small in the liquid phase of the reboiler, it was not possible to determine the actual retention time of reactants and catalyst in the reboiler. The effect of flow rate was mainly on the produce of methyl ester of the reactor. Fig. 7 shows that the \%weight of methyl ester decrease while the flow rate increase since the retention time is less. For the RD operation of setup in this study, the feed flow rate should not be higher $15 \mathrm{~mL} / \mathrm{min}$ in order to avoid flooding in column and this rate were considered as optimum range of operation.

\section{Steady state of biodiesel production by RD}

After the start of each experimental, the liquid product was checked for $\%$ methyl esters by gas chromatography to ensure that the system reached steady state, which was indicated by a constant value, after more than 8 hrs (fig.8). The system is unsteady state at higher temperature. Furthermore, the quantity of methyl ester is decreasing because the rates of soap formation rapidly increase at high temperature. It can block effective of system to produce methyl ester.

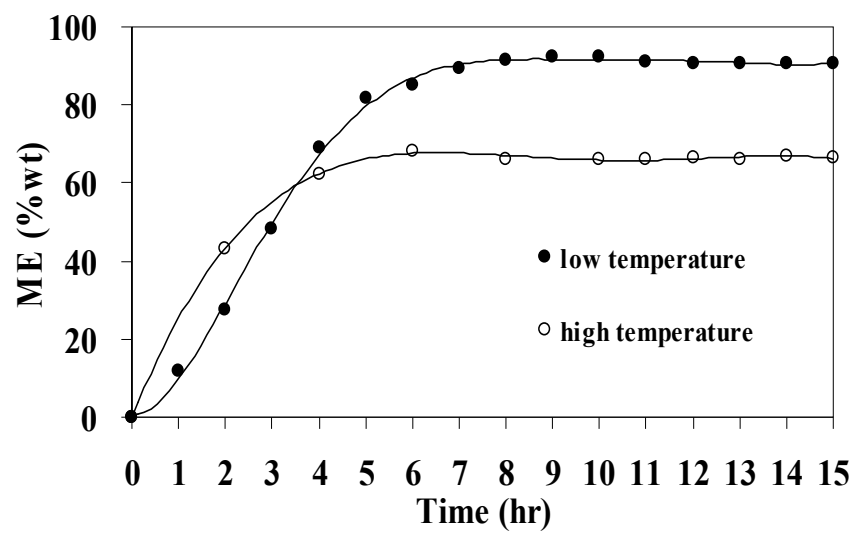

Figure 8: The effect of the reboiler temperature on methyl esters content in product. 


\section{Effect of reboiler temperature}

The function of reboiler is to vapourize the residual methanol presenting in the liquid reaching the bottom of the column. At steady state, the boiling-up rate of methanol is determined by the heat load in the reboiler, heat transfer efficiency and the amount of methanol in the reboiler. Methanol boils at $64.70 \mathrm{C}$, however, according to the experiments, sufficient methanol vapors were generated only with reboiler temperature higher than 900C. Depending upon the methanol concentrations, therefore, reboiler temperature in the experimental design varied from $800 \mathrm{C}$ to $1200 \mathrm{C}$ in order to produce smooth and consistent methanol vapor flow rates. It was found that the lower reboiler temperatures are favorable for better reactor performance (fig. 9). A possible reason is that with higher operating temperatures, the rates of soap formation increase more rapidly than that of transesterification.

The alkaline catalyst, potassium hydroxide concentration in the $1 \%$ (weight of $\mathrm{KOH} /$ weight of oil) is used in the present experimental. The effect of reboiler temperature on soap content in product is shown in fig. 10. Some catalyst in the high temperature process promotes the saponification reaction, thereby producing salts of fatty acids (soaps) and consuming the base, and thus inhibits the transesterification reaction. The quantity of soap accumulates when the reaction is carry on. In that manner, transesterification does not take place for superior amount of temperature elevation.
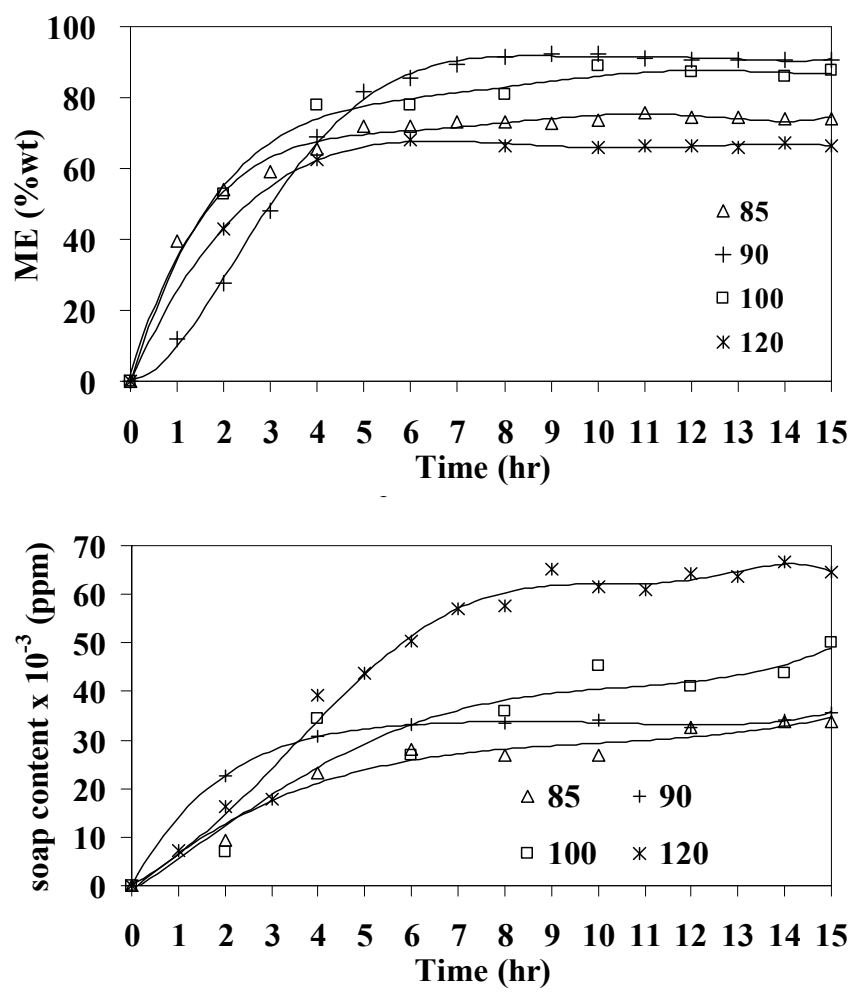

Figure 10: The quantity of soap in product at varying process time.

\section{Effect of methanol to oil ratio}

Fig. 11 shows the effect of time on methyl esters content in the product at varying methanol to oil ratio. The methyl ester content increases with molar ratio justifies the need for excess alcohol to drive the reaction to a higher yield. The methyl ester content in the product increases from $84.09 \%$ to $92.37 \%$ as the methanol to oil molar ratio increases from 3.0:1 to $5.0: 1$, which do not significantly increase the amount of methyl ester. And after that the methyl ester drop off due to flooding phenomena in the column. This result is brought about by excessive vapour flow, causing liquid to be entrained in the vapour up the column. The result of RD process shows that reaction of alcohol and palm oil in a ratio close to stoichiometric while excess alcohol is created by unreacted alcohol is vaporized from the reboiler.

\section{Quantity of methanol in product}

Normally, the conventional process is required 100 percent excess methanol to drive the reaction close to completion and to prevent the chemical equilibrium. The excess methanol remains from the reaction about $3.99 \% \mathrm{wt}$. Then the remainders of methanol have to recovery for reuse and reduce the operating cost. However, the reactive distillation has an amount of remained methanol lower than the conventional process (fig. 12). The result shows that the higher temperature has lower methanol content because of easier evaporation.

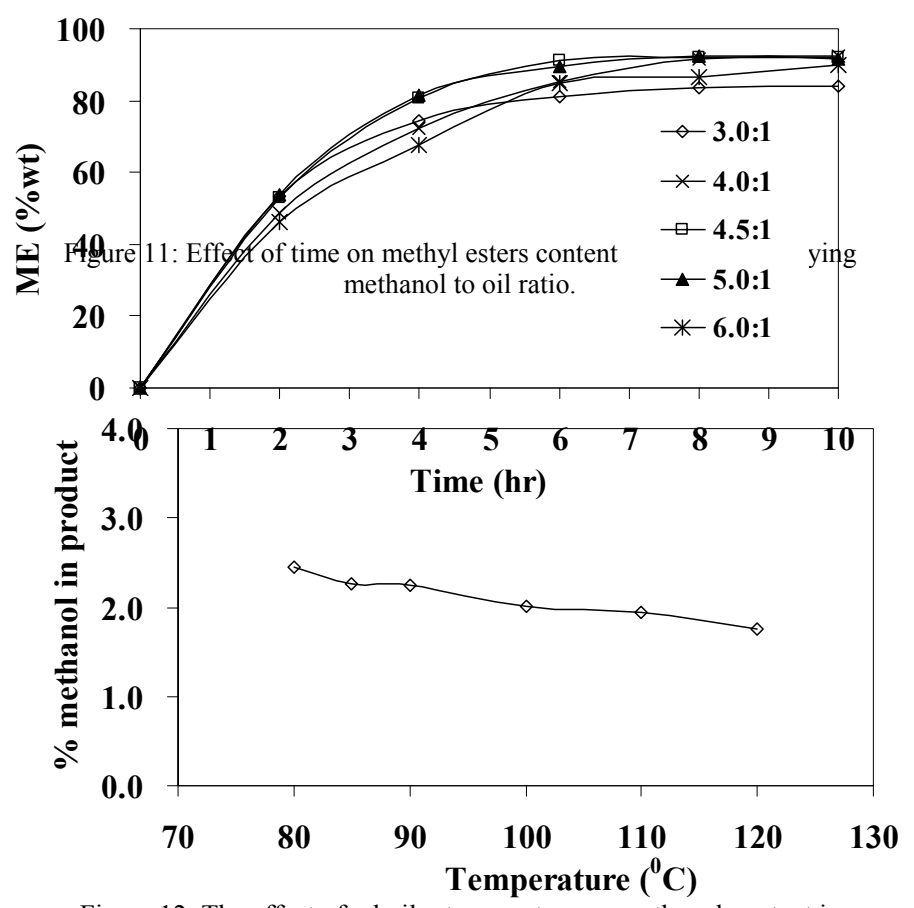

Figure 12: The effect of reboiler temperature on methanol content in product. 


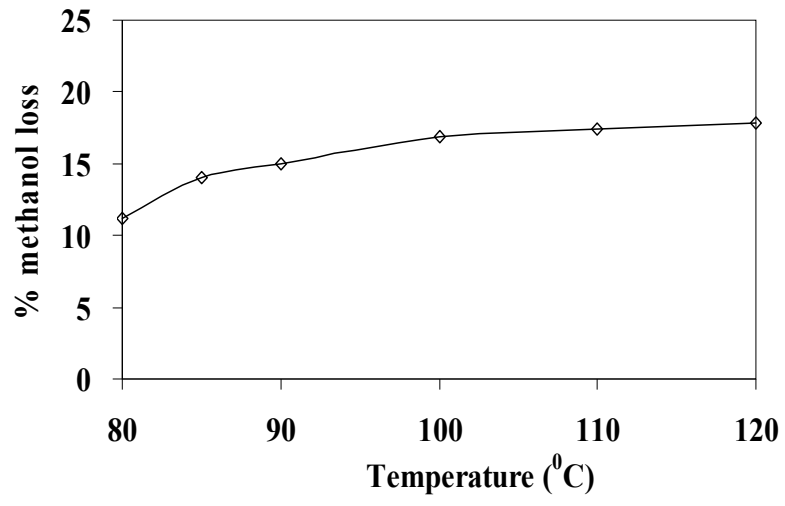

(a)

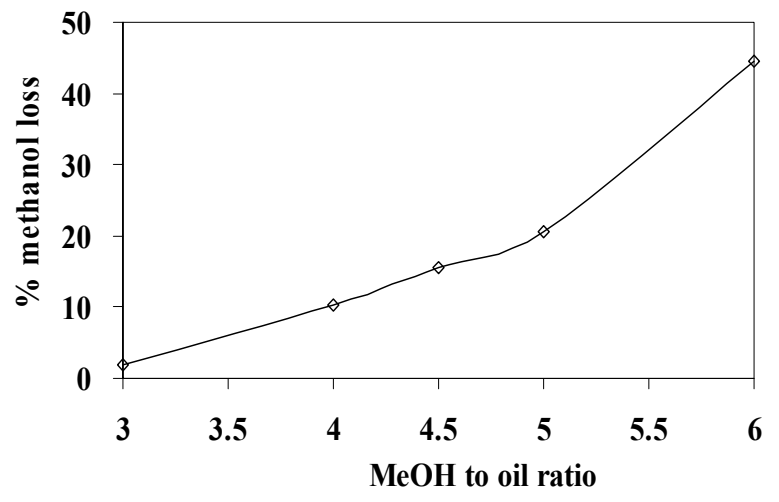

(b)

Figure 13: The quantity of methanol loss from system: (a) Temperature, (b) methanol to oil ratio

\section{Methanol balance of biodiesel production}

The transesterification is reversible reaction in which excess alcohol is required to drive the reaction close to completion. The excess alcohol must recover through distillation for reusing in conventional process. However, chemical reaction and methanol separation occur simultaneously in RD process. Unreacted alcohol is vaporized from the reboiler flow uphill to the top of column. The methanol in vapor phase can be losing from system. Fig. 13 shows that further increasing of temperature and methanol to oil ratio has significantly increased the percent of methanol loss.

The material balance shows the entire methanol associated in biodiesel production process. The result shows that there is much more mass input than output. In the process, oil and methanol are feed 13.65 and $2.08 \mathrm{~g}$, respectively. However, the methanol is needed in the reaction of transesterification only $1.56 \mathrm{~g}$ so that it has to remain $0.52 \mathrm{~g}$. On the other hand, the true output has only $0.44 \mathrm{~g}$ and some of it loss from the system.

\section{CONCLUSION}

The reactive distillation process is applied for production of biodiesel from palm oil. The original objective to reduce capital and investment cost of production process. The reduction of capital cost by carrying out the chemical reaction and distillation in the same equipment. Investment cost reduces by use methanol less than conventional and without energy for recovery and purify the excess methanol.

According to the results shows that RD process has been found to be feasible for the continuous production of biodiesel and can be concluded that the operating of RD process is better efficiency more than conventional process. Although, the product has \%purity of methyl ester less than standard, they are incline to be development and modify process to reach the standard. Based on of this study, the following conclusions are made; (1) the excess alcohol at the input was reduced. (2) Reaction time has been shortened. (3) Elevated temperature enhance high reaction rate.

\section{ACKNOWLEDGEMENTS}

The authors wish to express their acknowledgments to the Graduate School, Prince of Songkla University, Specialized
R\&D Center for Alternative Energy from Palm Oil and Oil Crops and Prince of Songkla University Graduate Studies Grant.

\section{REFERENCES}

[1] L.C. Meher, V.S.S. Dharmagadda and S.N. Naik. (2006, August). Optimization of alkali-catalyzed transesterification of Pongamia pinnata oil for production of biodiesel. Bioresource Technology. [Online]. 97(12). pp. 1392-1397. Available: http://www.sciencedirect.com/science/article/B6V24-4

[2] HTBKW3-1/2/8b5585e0acb233e287b06744f169c825

[3] N. Usta. (2005, January). Use of tobacco seed oil methyl ester in a turbocharged indirect injection diesel engine. Biomass and Bioenergy. [Online]. 28(1). pp. 77-86. Available: http://www.sciencedirect.com/ science/article/B6V22-4DB572V-1/2/a9f68633e450e8 fb0b492e8d63d306be

[4] D.Y.C. Leung and Y. Guo. (2006, October). Transesterification of neat and used frying oil: Optimization for biodiesel production. Fuel Processing Technology. [Online]. 87(10). pp. 883-890. Available: http://www.sciencedirect.com/science/ article/B6TG3-4KF1HNM1/2/b98aa43f0abb4390bbb 4c80d77f54b3a

[5] H. Harwood. (1984, February). Oleochemicals as a fuel: Mechanical and economic feasibility. Journal of the American Oil Chemists' Society. [Online]. 61(2). pp. 315-324. Available: http://dx.doi.org/10.1007 /BF02678788

[6] J.M. Marchetti, V.U. Miguel and A.F. Errazu. (2007, August). Possible methods for biodiesel production. Renewable and Sustainable Energy Reviews. [Online]. 11(6). pp. 1300-1311. Available: http://www.science direct.com/science/article/B6V MY4HPCP19-1/2/9e0fa125c4bf00a168df02b4364a 81f4

[7] K. Kapilakarn and A. Peugtong. (2007, March). A comparison of costs of biodiesel production from transesterification. International Energy Journal. [Online]. 8(1). pp. 1-6. Available: http://www.rericjournal.ait.ac.th/index.php/reric/article/ viewFile/170/132

[8] S. Bhatia, A. L. Ahmad, A. R. Mohamed and S. Y. Chin. (2006, November). Production of isopropyl palmitate in a catalytic distillation column: Experimental studies. Chemical Engineering Science. [Online]. 61(22). pp. 7436-7447. Available: http://www.sciencedirect.com/science/a rticle/B6TFK-4KSHB91$1 / 2 / 6487 \mathrm{cb} 81 \mathrm{db} 725 \mathrm{~d} 31927 \mathrm{~b} 16566 \mathrm{f} 32 \mathrm{a} 954$

[9] M. Brehelin, F. Forner, D. Rouzineau, J. U. Repke, X. Meyer, M. Meyer and G. Wozny. (2007, October). Production of n-Propyl Acetate by Reactive Distillation: Experimental and Theoretical Study. Chemical Engineering Research and Design. [Online]. 85(1). pp. 109-117. Available: http://www.sciencedirect.com/science/article/B8JGF-4S4SKB7F/2/e28df9f2d1b89ffc5a45bae45b1662 60

[10] C. Venkateswarlu and B. Jeevan Kumar. (2006, September). Composition estimation of multicomponent reactive batch distillation with optimal sensor configuration. Chemical Engineering Science. [Online]. 61(17). pp. 5560-5574. Available: http://www.sciencedirect.com/science/article/B6TFK-4JW0WSB6/2/c31500f1fe9cc9227ffa7142a7 b1c728

[11] K.-L. Zeng, C.-L. Kuo and I.L. Chien. (2006, July) Design and control of butyl acrylate reactive distillation column system. Chemical 
Engineering Science. [Online]. 61(13). pp. 4417-4431. Available: http://www.sciencedirect.com/science/article/B6TK-4JP9G10-

2/2/058907be8838d79b96fd0ebd470 ead3b

[12] R. Thery, X. M. Meyer, X. Joulia and M. Meyer. (2005, April). Preliminary Design of Reactive Distillation Columns. Chemical
Engineering Research and Design. [Online]. 83(4). pp. 379-400. Available: http://www.sciencedirect.com/science/ article/B8JGF4RT04W5-7/2/79461054f2dac7f096 176fa2ba6b2055 